\title{
Effect of thrust and torque exerted during drilling to optimize exit burr height and thickness by choosing variable drill bit geometry: A simplified theoretical model approach
}

\author{
R. Sreenivasulu ${ }^{a^{*}}$, Ch. Srinivasa Rao $^{b}$ and K. Ravindra ${ }^{a}$
}

\begin{abstract}
${ }^{a}$ Department of Mechanical Engineering, R.V.R. \& J.C.College of Engineering (Autonomous), Chowdavaram, Guntur, Andhra Pradesh, India ${ }^{b}$ Department of Mechanical Engineering, University College of Engineering, (Autonomous) Andhra University, Visakhapatnam, Andhra Pradesh, India

C H R O N I C L E

Article history:

Received: July 1, 2019

Received in revised format: July 22, 2019

Accepted: August 30, 2019

Available online: August 30, 2019

Keywords:

Drilling

Aluminium alloys

Burr formation

Thrust force

Torque

Analytical modelling

A B S T R A C T

In precision manufacturing, especially in making of holes on the parts during drilling process for precision assembling of parts facing problems with burr formation. Drilling is one of the finishing operations in the production cycle, removal of burrs during drilling process is a time consuming and non-value added process to the manufacturing sector. In this paper, we developed an analytical models for thrust force, torque and burr size with variable clearance angle of drill bit geometry especially for Aluminium alloys used for automotive applications. An analytical model results were obtained by writing a code in MATLAB @ 2010 software for aluminium alloy series such as $\mathrm{Al}$ 6061, Al 2014 and Al 7075. In an economic front, developed mathematical models are benefitted to reduce experimentation, these results reveal that at the beginning of the drilled hole due to indentation of chisel edge, more thrust and torque was identified, beyond that suddenly thrust force was lowered, cutting forces by the lip edges were increased from beginning of the process to progress of drilling process. The proposed model approach is helpful to the budding entrepreneurs in the related areas to select optimal combination of drilling parameters to attain multiple performance characteristics of responses especially in burr size to prevent the post finishing operations up to certain extent.
\end{abstract}

\section{Introduction}

As manufacturing processes has become advanced, precision components require more attention to both the generation of surfaces and dimensions with tight tolerances. High quality products should be precisely manufactured according to the design specifications with minimal costs. To satisfy these requirements, the manufacturing process should be understood and its parameters need to be optimized (Armarego,1996). Drilling is one of the final finishing operations while in assembly sections used in a variety of manufacturing industries including aerospace and automotive sectors (Armarego \& Cheng, 1972). An unwanted projection of material formed during the drilling process, termed as burr as a part size errors

\footnotetext{
* Corresponding author.

E-mail address: rslu1431@gmail.com (R. Sreenivasulu) 
(Fig. 1). Burr is plastically deformed material, generated on the part edge during cutting or shearing (Aurich et al., 2009; Chandrasekharan et al., 1995a, 1998b). Wherever conventional drilling is carried out, the burr formation of sheared edge is inevitable. Removal of burr is essential for any component to avoid damage of component after assembling due to abrasion, injuring workers while assembling and other related problems. So, elimination of burr is mandatory which involves some cost, literally known as Deburring cost.

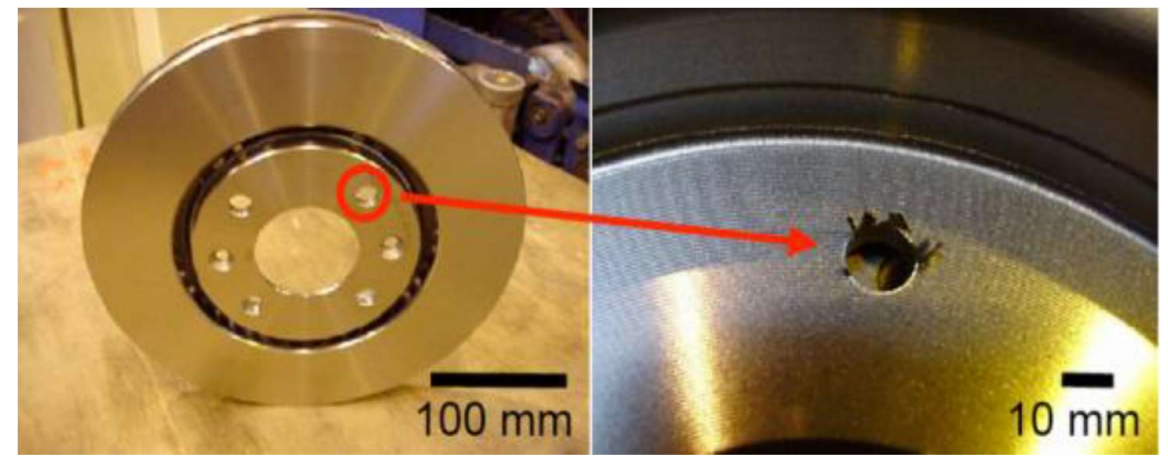

Fig. 1. Micro image of burr formation on Flange (2)

Aurich et al. (2009) also identified, the investment on removing of burrs is non value added process, while estimating manufacturing cost and pie diagram representation (shown in Fig. 2a \& Fig. 2.b) of cost incurred on burr removal process in an excellent manner to understand, why the present industries affected more towards non value added deburring cost?

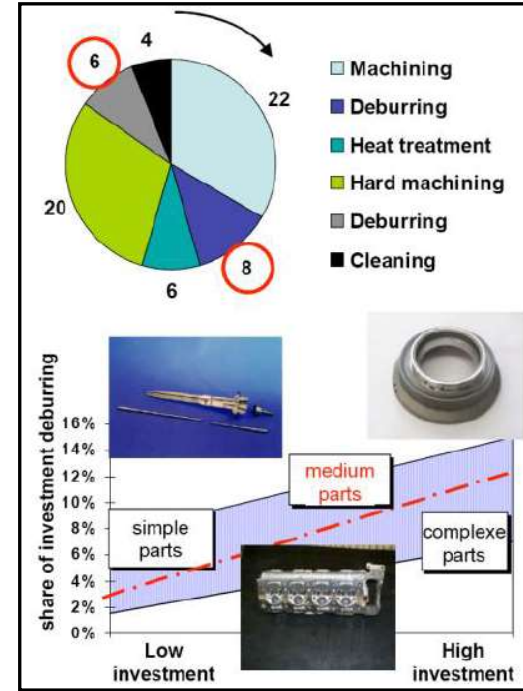

Fig. 2a. Breakdown of manufacturing expenses

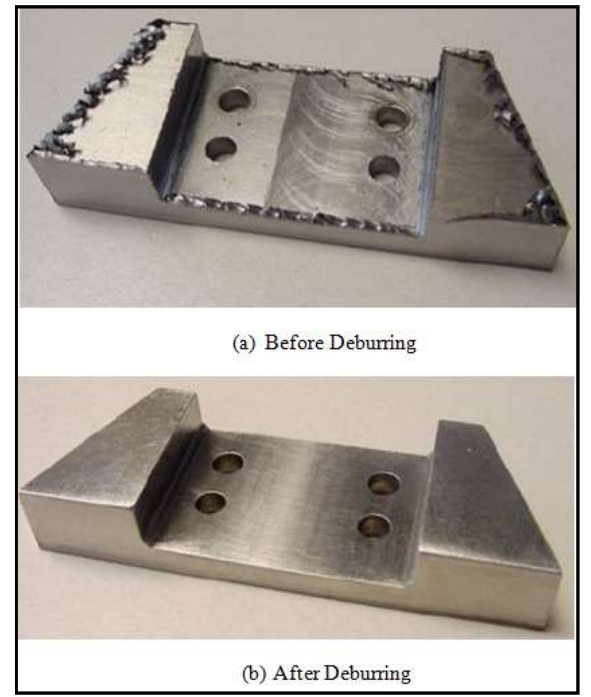

Fig. 2b. Image of milled component after deburring

\section{Analytical modeling techniques for Burr formation}

A new simplified method is proposed by Armarego and Cheng (1992) to predict thrust and torque during drilling for conventional and modified drills. The method of calculation was also based on the implementation of both the orthogonal cutting model and the oblique cutting model. Stephenson and Agapiou (1992) developed a static force model for drills with various geometrical parameters. The proposed models did not include the effect of the chisel edge in their model, but like other researchers, the authors focused on the primary cutting edge and split it into small segments. Chandrasekharan et al. $(1995,1998)$ suggested a new approach in predicting the cutting forces for drilling based on the geometric similarity of the drills. In the predicted model, the force and torque Equations were represented in a normalized radial coordinate system. Their model consists of two main points of interest: the primary cutting edge 
and the chisel edge. In order to describe the cutting forces on the primary cutting edges used the Merchant's model and the calculations for the chisel edge were based on the slip line field method derived by Kachanov (2004). Elhachimi et al. (1999), based on the oblique cutting model for the primary cutting edge and the orthogonal cutting model for the chisel edge presented a new theoretical model to predict thrust force and torque in high speed drilling. Chen et al. (1996) modified the existing force model for the split-point, incorporating the splitting parameters on the secondary cutting edge for predicting the thrust force and torque. Kapoor et al. (1998), Chandrasekharan et al. (1998), Gong et al. (2001, 2005) and Elhachimi et al. (1999) developed various mechanistic drilling models based on basic principles of metal cutting. Other recent developments in drilling models have utilized the finite element method Strenkowski et al. (2004) developed an analytical finite element technique for predicting the thrust force and torque in drilling with twist drills. The approach was based on representing the cutting forces along the cutting edge as a series of oblique sections and cutting in the chisel edge region was treated as an orthogonal metal cutting with various types of speeds depending on the radial positions with respect to the axis.

In the present work, analytical model for predicting exit burr height $\left(\mathrm{B}_{h}\right)$ and thickness $\left(\mathrm{B}_{\mathrm{t}}\right)$ are developed, which is divided in to three parts viz., (1) To develop simplified model for drill thrust and torque, (2)Finding burr initiation height and (3) Finding final burr height and thickness. In the first part, a model is developed to determine thrust force and torque during drilling process. Oxford Jr (1955) proposed a model for aluminium alloys to estimate thrust force $\left(\mathrm{F}_{\text {th }}\right)$ and torque $(\mathrm{M})$ by considering drill bit geometry, material properties and process parameters, which can be considered as base model and modify it by altering the value of the constant ' $K$ ' value provided in the model (Eq. 1).

$$
\begin{aligned}
& \frac{F_{t h}}{d^{2} * H_{B}}=0.55 *\left(\frac{f^{0.8}}{d^{1.2}}\right) *\left[\left(\frac{1-K}{\left((1-K)^{0.2}\right)}\right)+2.2 * K^{0.8}\right]+0.07 K^{2} \\
& \frac{M}{d^{3}} * \frac{1}{H_{B}}=0.03 * \frac{f^{0.8}}{d^{1.2}} *\left[\left(\frac{1-K^{2}}{\left((1+K)^{0.2}\right)}\right)+3.2 * K^{1.8}\right]
\end{aligned}
$$

where,

$$
\begin{aligned}
& F_{t h}=\text { Axial force or Thrust Force during drilling, } \mathrm{kgf} \\
& M=\text { Torque or Moment of a cutting force of the drill on chisel edge, kg-cm } \\
& H_{B}=\text { Brinell hardness of the material }(\mathrm{BHN}) \\
& d=\text { diameter of the twist drill in ' } \mathrm{mm} \text { ' } \\
& f=\text { feed rate in } \mathrm{mm} / \mathrm{rev} \\
& K=\text { ratio of chisel edge length to drill diameter }=\frac{c}{d}
\end{aligned}
$$

While drilling, the drill bit is subjected to the action of the cutting force, which can be conveniently resolved into three components viz., a tangential component $\left(\mathrm{F}_{\mathrm{z}}\right)$, a radial component $\left(\mathrm{F}_{\mathrm{y}}\right)$ and an axial component which is commonly referred as the thrust force in drilling $\left(\mathrm{F}_{\text {th }}\right)$ as shown in Fig. 3. 

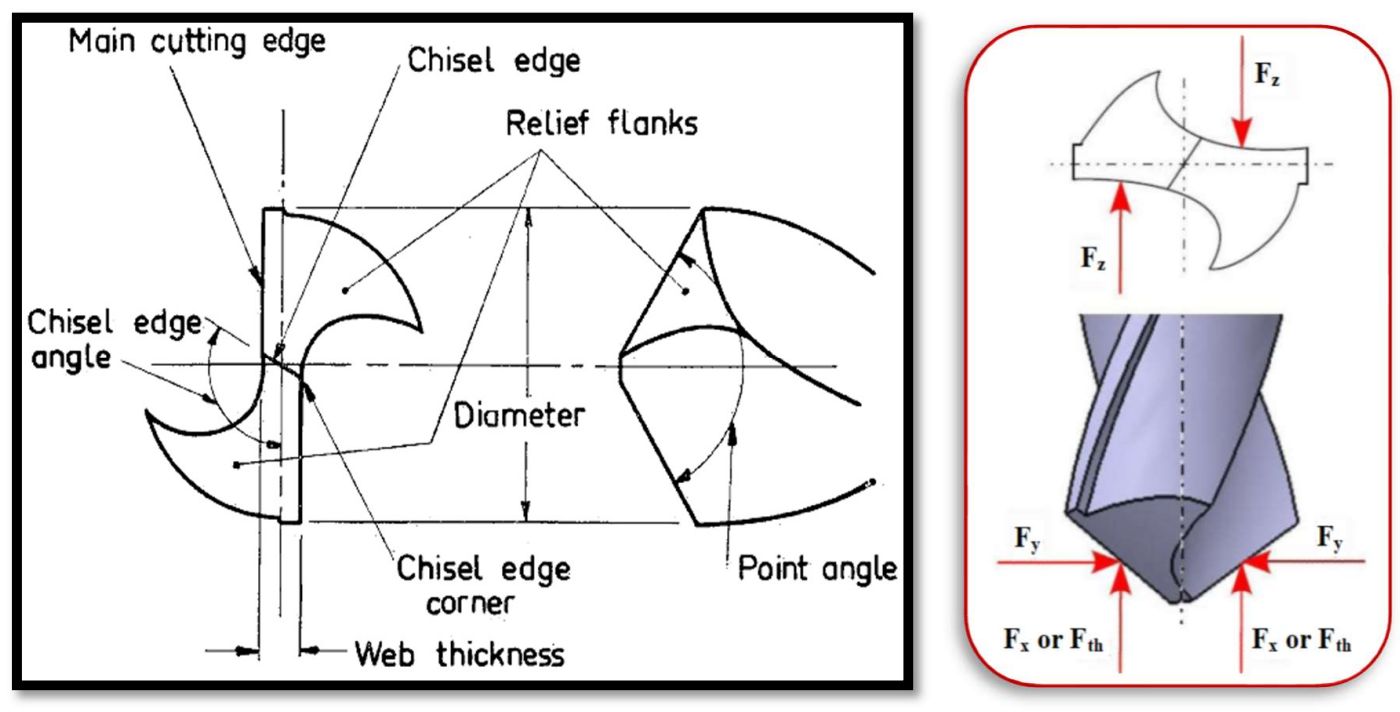

Fig. 3. Cutting edge geometry of a drill and Cutting forces during drilling

The extrusion torque at the chisel edge is negligible and the torque acting on the drill bit is mainly constituted by the tangential force $\left(\mathrm{F}_{\mathrm{z}}\right)$. The radial components $\left(\mathrm{F}_{\mathrm{y}}\right)$ on both the lips usually cancels out. Various empirical formulae exist for the calculation of axial force $\left(\mathrm{F}_{\text {th }}\right)$ and torque $(\mathrm{M})$. The feed angle

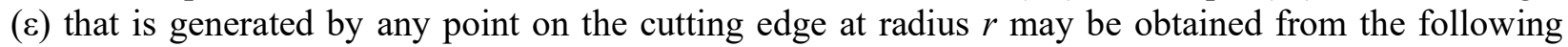
expression in terms of the feed per revolution of the drill (f):

$$
\begin{aligned}
& \varepsilon=\tan ^{-1}\left(\frac{f}{2 \pi r}\right) \\
& \operatorname{Sin}(\pi-\gamma)=\frac{\text { web thickness }}{\text { chisel edge length }} \\
& c=\frac{\text { web thickness (w) }}{\cos \alpha \sin (\pi-\gamma)}
\end{aligned}
$$

In the present work, the alteration of clearance and point angles carried out under the presence of a skilled operator on Tool \& Cutter grinding machine to attain desired dimensions. Due to change of clearance angle on drill, it causes variation in the chisel edge length and simultaneously influence on web thickness. In general, chisel edge length can be calculated from geometry of the drill bit shown in Fig. 4. Using the equations 1 and 2 , thrust force and torque are determined by substituting the modified constant ' $\mathrm{K}$ ', which is obtained from the equation $2 \mathrm{a}$ by substituting the given parameters

\section{Burr initiation height $\left(\mathbf{H}_{1}\right)$}

In the second part, to develop a model for burr initiation height $\left(\mathrm{H}_{1}\right)$, an assumption is made that burr initiation begins when the power input due to the drilling force vector and its velocity is equivalent to the power required to shear the supporting slab of material as shown in below Fig. 5.

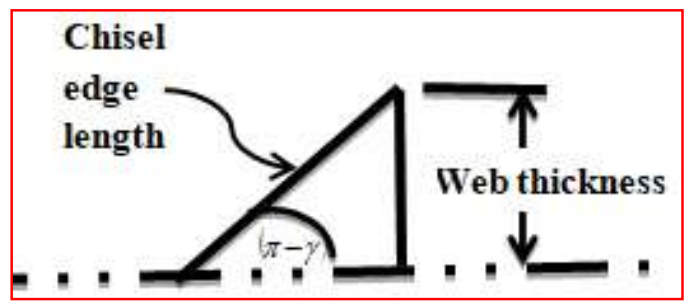

Fig.4 Geometry of the chisel edge 


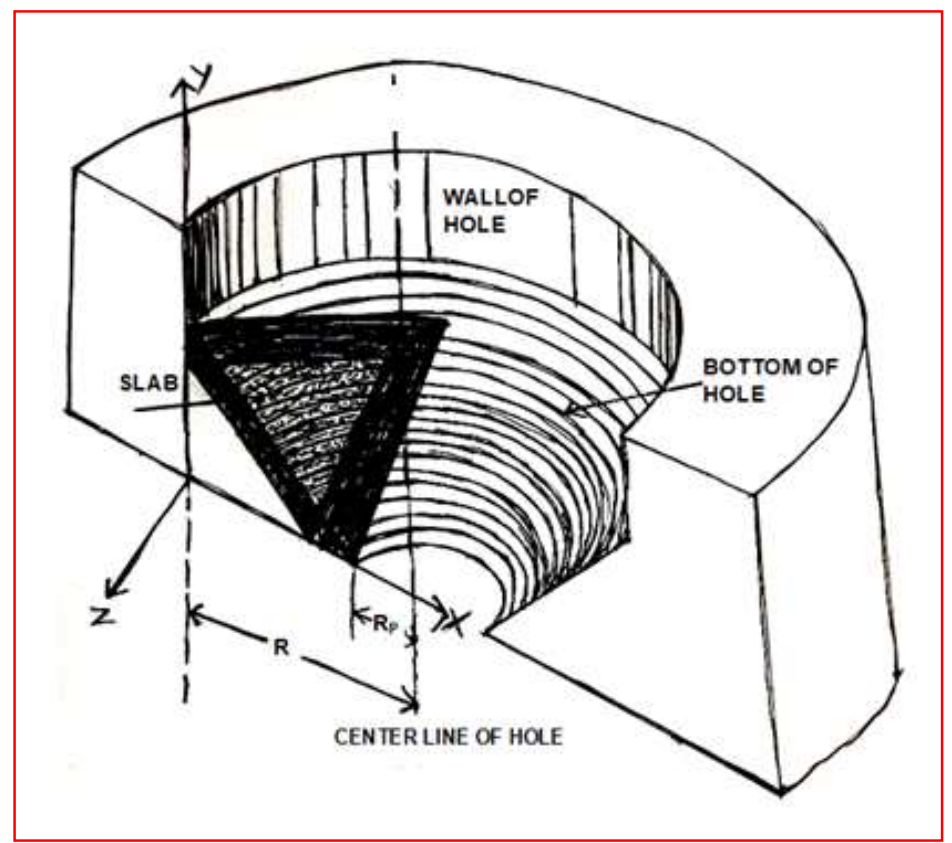

Fig. 5. Burr initiation height parameters

$\tau_{\omega}=$ Shear strength of the material, $\frac{\mathrm{N}}{\mathrm{mm}^{2}}$

$\overline{V_{\text {drill }}}=$ Peripheral velocity vector of the drill bit, $\mathrm{m} / \mathrm{s}$

$\overline{V_{\text {slab }}}=$ Relative velocity vector for the sheared slab material, $\mathrm{m} / \mathrm{s}$

$\bar{F}=$ Total drilling force vector on chisel edge, $\mathrm{N}$

$|\bar{A}|=$ Magnitude of the area needed to be sheared, $\mathrm{mm}^{2}$

The governing equation for finding the initiation height is,

Drilling Power input $=$ power required to shear the supporting slab material

$$
\bar{F} * \overline{V_{\text {drill }}}=\tau_{\omega} *|\bar{A}| * \overline{V_{\text {slab }}}
$$

However, the drill velocity and the relative velocity of the sheared slab material are the same. Therefore,

$$
\bar{F}=\tau_{\omega} *|\bar{A}|
$$

where $\bar{F}=$ scalar magnitude of force in the direction of the slab's motion.

In the Eq. (6) and Eq. (7) involved vector terms, which are simplified by Williams (1974) and Gong et al. (2001and 2005) in terms of shear strength of material, burr initiation height, cutting force on chisel edge and drill geometry, which is equivalent to Eq. (7) is given in Eq.8 below.

$$
\begin{aligned}
& \frac{F_{Z}}{\left(\tau_{\omega} H_{1}^{2}\right)}=\varepsilon \tan \beta\left(\frac{\cos (\mu-\vartheta)}{\sin \varphi \cos (\varphi+\mu-\vartheta)}\right) \\
& F_{Z}=\varepsilon\left(\tau_{\omega} H_{1}^{2}\right) \tan \beta\left(\frac{\cos (\mu-\vartheta)}{\sin \varphi \cos (\varphi+\mu-\vartheta)}\right)
\end{aligned}
$$


Sofronas (1976), Armarego (1996), Chandrasekharan et al. (1995, 1998), used the following expression for ' $\varepsilon$ '

$$
\mathcal{E}=\text { ratio of drill feed to the initiation height }=\frac{\mathrm{f}}{2 \mathrm{H}_{1}}
$$

From the geometry of drill bit, Sofronas (1976) and Williams (1974) derived the following expression relating the cutting force $\left(\mathrm{F}_{\mathrm{z}}\right)$ to the thrust force $\left(\mathrm{F}_{\mathrm{th}}\right)$ in their work. In the present work, the same equations are utilized to simplify the present model.

$$
F_{Z}=\frac{F_{t h}}{\sin \beta \tan (\mu-\vartheta)}
$$

' $\vartheta$ ' is found from the expressions given by

$$
\tan \vartheta=\frac{\left(1-q^{2} \sin ^{2} \beta\right)}{\sqrt{\left(1-q^{2}\right)}} * \frac{\tan \delta}{\sin \beta}-\frac{(q \cos \beta)}{\sqrt{\left(1-q^{2}\right)}},
$$

where, $\delta=$ Helix angle and

$$
\begin{aligned}
& q=\frac{\text { web thickness of the drill bit in } \mathrm{mm}}{\text { diameter of the drill bit in } \mathrm{mm}}, \\
& \mu=\frac{\pi}{6}+\frac{\vartheta}{2} .
\end{aligned}
$$

Once determine the value 'q' from Eq. (12), then calculate the normal rake angle $\vartheta$ from Eq. (11) and friction angle from Eq. (13) then by plugging Eq. (1) and Eq. (10) to predict the cutting force on the chisel edge of a twist drill $\left(\mathrm{F}_{\mathrm{z}}\right)$. The burr initiation height model works through an energy rate balance equation which finds the point at which the downward cutting force of the drill is equivalent to the force required to plastically deform the remaining material underneath the drill into a burr. The model then assumes that the remaining material under the drill no longer gets cut and completely plastically deforms into the final burr shape, so for this purpose first predict the position of shear plane (angle ' $\varphi$ '). Several theories are found from literature, out of which, Earnst Merchant (minimum energy criterion) that is shear plane is located where least energy is required for shearing of the material from work piece while metal cutting. Therefore, shear plane angle is found by applying condition for minimum energy, According to that,

$$
\frac{d F_{Z}}{d \varphi}=0 \text {, }
$$

where, $F_{Z}=$ Cutting force of the drill on chisel edge

According to Stabler shear plane angle,

$$
\varphi=\frac{\pi}{4}+\frac{\vartheta-\mu}{2},
$$

Substitute Eq. (8.1) and Eq. (9) into Eq. (10), we get,

$$
\begin{aligned}
& \varepsilon\left(\tau_{\omega} H_{1}^{2}\right) \tan \beta\left(\frac{\cos (\mu-\vartheta)}{\sin \varphi \cos (\varphi+\mu-\vartheta)}\right)=\frac{F_{t h}}{\sin \beta \tan (\mu-\vartheta)} \\
& H_{1}=\frac{2 * F_{t h} * \sin \varphi * \cos (\varphi+\mu-\vartheta)}{\tau_{\omega} * f * \tan \beta * \cos (\mu-\vartheta) * \sin \beta * \tan (\mu-\vartheta)}=\frac{2 * F_{t h} * \sin \varphi * \cos (\varphi+\mu-\vartheta)}{\tau_{\omega} * f^{*} \tan \beta * \cos (\mu-\vartheta) * \sin \beta *\left(\frac{\sin (\mu-\vartheta)}{\cos (\mu-\vartheta)}\right)} \\
& H_{1}=\frac{2 * F_{t h} * \sin \varphi * \cos (\varphi+\mu-\vartheta)}{\tau_{\omega} * f * \sin \beta * \tan \beta * \sin (\mu-\vartheta)}
\end{aligned}
$$


In the above Eq. (14), the value obtained for thrust force $\left(\mathrm{F}_{\text {th }}\right)$ is minimized value because it is derived based on the condition of minimum energy. Once the point at which the downward thrust force (minimum) of the drill is equal to the force required to plastically deform the remaining material into a burr is known then move to final step that is finding final burr height.

\section{Final burr geometry}

After the burr initiation height is found, it is assumed that no additional material is cut, and that all of the remaining material is bent downwards into the final exit burr shape, which is shown in Fig.6 as a triangular element represented in red color

Elemental volume of initiation of burr $=$ Elemental volume of final exit burr

$2 \pi r \times h_{1} \times d r=2 \pi R \times t \times d h$ Rearranging and in logarithmic form,

$$
\ln \left(\frac{R}{r}\right)+\ln \left(\frac{d h}{d r}\right)+\ln \left(\frac{t}{h_{1}}\right)=0
$$

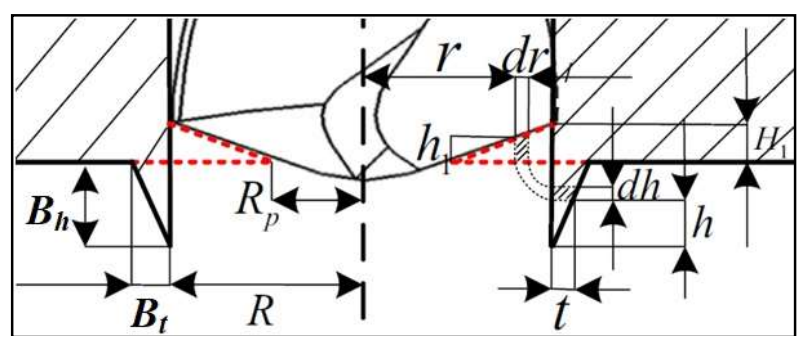

Fig. 6. Exit burr formation and parameters

From the geometry of the element considered in the above fig.6, the variable ' $h_{1}$ ' can be rewritten and substituted into the Eq. (17)

$$
h_{1}=\frac{r-R_{P}}{\tan \beta} \quad \ln \left(\frac{R}{r}\right)+\ln \left(\frac{d h}{d r}\right)+\ln \left(\frac{t}{\left(\frac{r-R_{P}}{\tan \beta}\right)}\right)=0
$$

From Miyake et al. (1991) deformation model theory, Eq. (17) is equivalent to Eq. (17a)

$$
\varepsilon_{\theta}+\varepsilon_{r}+\varepsilon_{t}=0
$$

where, $\varepsilon_{\theta}$ is the circumferential strain, $\varepsilon_{\mathrm{r}}$ is the radial strain and $\varepsilon_{\mathrm{t}}$ is the thickness strain. It is assumed that only radial stress is present, such that $\varepsilon_{\theta}=\varepsilon_{\mathrm{t}}$, which implies,

$$
\begin{aligned}
& \mathcal{E}_{r}=-2 * \varepsilon_{\theta} \\
& \ln \left(\frac{d h}{d r}\right)=-2 \ln \left(\frac{R}{r}\right) \\
& \frac{d h}{d r}=\frac{r^{2}}{R^{2}} \quad \text { Integrate on both sides } \\
& \int_{0}^{h} R^{2} d h=\int_{R_{P}}^{r} r^{2} d r
\end{aligned}
$$




$$
\begin{aligned}
& h=\frac{\left(r^{3}-R_{p}^{3}\right)}{3 \times R^{2}}, \\
& B_{h}=\frac{\left(R^{3}-R_{P}^{3}\right)}{3 * R^{2}},
\end{aligned}
$$

where $\mathrm{R}_{\mathrm{p}}=\mathrm{R}-\mathrm{H}_{1} \tan \beta$ through geometry from Fig. 6 and $\varepsilon_{\theta}=\epsilon_{t}$

$$
\ln \left(\frac{R}{r}\right)=\ln \left(\frac{t}{\left[\frac{r-R_{P}}{\tan \beta}\right]}\right) \quad \frac{R}{r}=\frac{t}{\left[\frac{r-R_{P}}{\tan \beta}\right]} \quad r=\frac{R * R_{P}}{R-t * \tan \beta}
$$

Plugging this value of $r$ into the Eq. (18),

$$
\begin{aligned}
& h=\frac{\left(\frac{R * R_{p}}{R-t^{*} \tan \beta}\right)^{3}-R_{p}^{3}}{3 R^{2}} \\
& \left(3 * R^{2} * h+R_{p}^{3}\right)^{\frac{1}{3}}=\frac{R^{*} R_{p}}{R-t^{*} \tan \beta} \\
& R-t^{*} \tan \beta=\frac{R^{*} R_{p}}{\left(3 * R^{2} * h+R_{p}^{3}\right)^{\frac{1}{3}}}=\frac{R^{*}\left(R_{p}^{3}\right)^{\frac{1}{3}}}{\left(3 * R^{2} * h+R_{p}^{3}\right)^{\frac{1}{3}}} \\
& t=\frac{R-\left(R^{*}\left(R_{p}^{3}\right)^{\frac{1}{3}}\right)}{\left(3 * R^{2} * h+R_{p}^{3}\right)^{\frac{1}{3}} * \tan \beta} \\
& t=\frac{R}{\tan \beta}\left[1-\left(\frac{R_{P}^{3}}{3 * R^{2} * h+R_{P}^{3}}\right)^{\frac{1}{3}}\right] \text { Substituting in } h=\mathrm{B}_{\mathrm{h}} \text { and } t=\mathrm{B}_{\mathrm{t}} \text { results in: } \\
& B_{t}=\frac{R-R_{P}}{\tan \beta}=H_{1}
\end{aligned}
$$

From the Eq. (1), Eq. (2), Eq. (18) and Eq. (20), the thrust force, torque, burr height and burr thickness can be found.

\section{Results and discussion}

The developed analytical models for thrust force $\left(\mathrm{F}_{\text {th }}\right)$, torque $(\mathrm{M})$, burr height $\left(\mathrm{B}_{\mathrm{h}}\right)$ and burr thickness $\left(B_{t}\right)$ depicted in the Eq. (1), Eq. (2), and Eq. (20), respectively and solved by using MATLAB@2010. In MATLAB, developed a program by using the input data viz., geometry of chisel edge, drill bit geometry, machining conditions and mechanical properties of work piece from Tables 1 to 4 . Web thickness values are measured using Tool maker's microscope are also incorporated into MATLAB in a coded form. In the first step, the thrust force and torque codes are developed using the Eq. (1) and Eq. (2), under analytical modelling and put into the sub routine program file, which helps to recall whenever the data is required for further computations. Then, for burr initiation height, generate a code by combining the Eq. 
(8) and Eq. (10) together and prior to this a code is generated to minimize the cutting force $\left(\mathrm{F}_{\mathrm{z}}\right)$ using Eq. 14 and Eq. 15 by recalling the sub routine program of assessing the thrust force $\left(\mathrm{F}_{\text {th }}\right)$.

Table 1

Geometry of chisel edge

\begin{tabular}{ccc}
\hline Drill diameter $(\mathbf{d}), \mathbf{m m}$ & Clearance angle $(\alpha)$ degrees & Half of the web thickness $(\omega)$ degrees \\
\hline $\mathbf{8}$ & 4 & 0.6 \\
& 6 & 0.8 \\
$\mathbf{1 0}$ & 8 & 1.2 \\
& 4 & 1.6 \\
& 6 & 1.4 \\
$\mathbf{1 2}$ & 8 & 1.2 \\
& 4 & 2.8 \\
& 6 & 2.4 \\
\hline
\end{tabular}

\section{Table 2}

Drill bit geometrical parameters

\begin{tabular}{lccc}
\hline Parameter & Unit & Symbol & Value \\
\hline Diameter & $\mathrm{mm}$ & $\mathrm{D}$ & $8,10,12$ \\
Helix angle & degrees & $\delta$ & $30^{\circ}$ constant \\
point angle & degrees & $2 \beta$ & $100^{\circ}, 110^{\circ}, 118^{\circ}$ \\
Chisel edge angle & degrees & $\gamma$ & $136^{\circ}$ constant \\
Clearance angle & degrees & $\alpha$ & $4^{\circ}, 6^{\circ}, 8^{\circ}$ \\
Feed rate & $\mathrm{mm} / \mathrm{min}$ & $\mathrm{f}$ & $18,20,26$ \\
Spindle speed & $\mathrm{rpm}$ & $\mathrm{N}$ & $465,695,795$ \\
\hline
\end{tabular}

Table 3

Machining parameters

\begin{tabular}{lccc}
\hline Parameter & Unit & Symbol & Value \\
\hline Feed rate & $\mathrm{mm} / \mathrm{min}$ & $\mathrm{f}$ & $18,20,26$ \\
Spindle speed & $\mathrm{rpm}$ & $\mathrm{N}$ & $465,695,795$ \\
\hline
\end{tabular}

\section{Table 4}

Work piece mechanical properties

\begin{tabular}{lccccc}
\hline Parameter & Unit & Symbol & \multicolumn{3}{c}{ Value } \\
\cline { 3 - 6 } & & & Al 6061 & Al 2014 & Al 7075 \\
\hline Shear strength & $\mathrm{N} / \mathrm{mm}^{2}$ & $\tau_{\mathrm{w}}$ & 207 & 290 & 331 \\
Brinell hardness & & $\mathrm{BHN}$ & 81 & 96 & 111 \\
\hline
\end{tabular}

To find the final burr height and thickness, fifty elements are selected along the cutting lip plane at a radial distance $\left(\mathrm{R}_{\mathrm{p}}\right)$ from the axis of rotation of the drill bit and write a program by using Eq.20 and results are tabulated. Using the data, plot the graphs between the output responses versus experimental runs and also plot with individual input parameters to identify the influence on output responses.

\subsection{Spindle speed influence on output responses}

The graph shown in Fig. 7 reveals that maximum and minimum values of burr height obtained for Al 7075 alloy i.e. at the higher spindle speed and feed rates, lower point and clearance angles causes reduction in the burr height. 


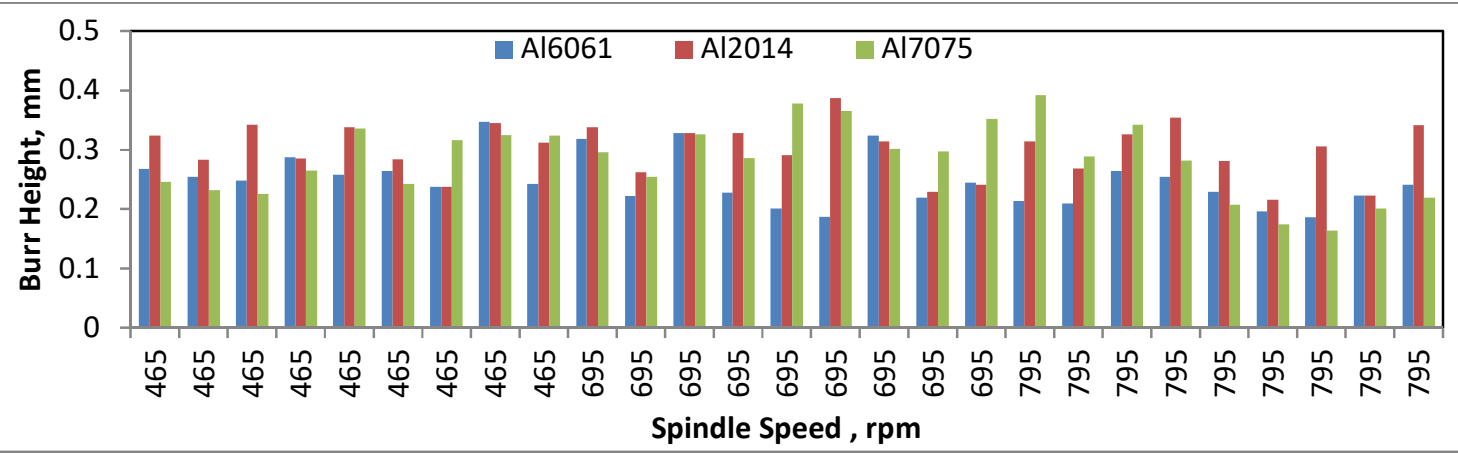

Fig. 7. Effect of variation of the spindle speed on burr height

The graph shown in Fig. 8 projects the maximum and minimum values of burr thickness obtained for $\mathrm{Al}$ 2014 alloy i.e. at the higher the feed rates, point and clearance angles yields an increase in the burr thickness value. It is also observed that at higher spindle speeds and lower drill geometry, the reduction in the thickness of burr. Similarly, an aluminium 6061 and 7075 alloy shows marginal deviation towards burr thickness even though the spindle speed enhances.

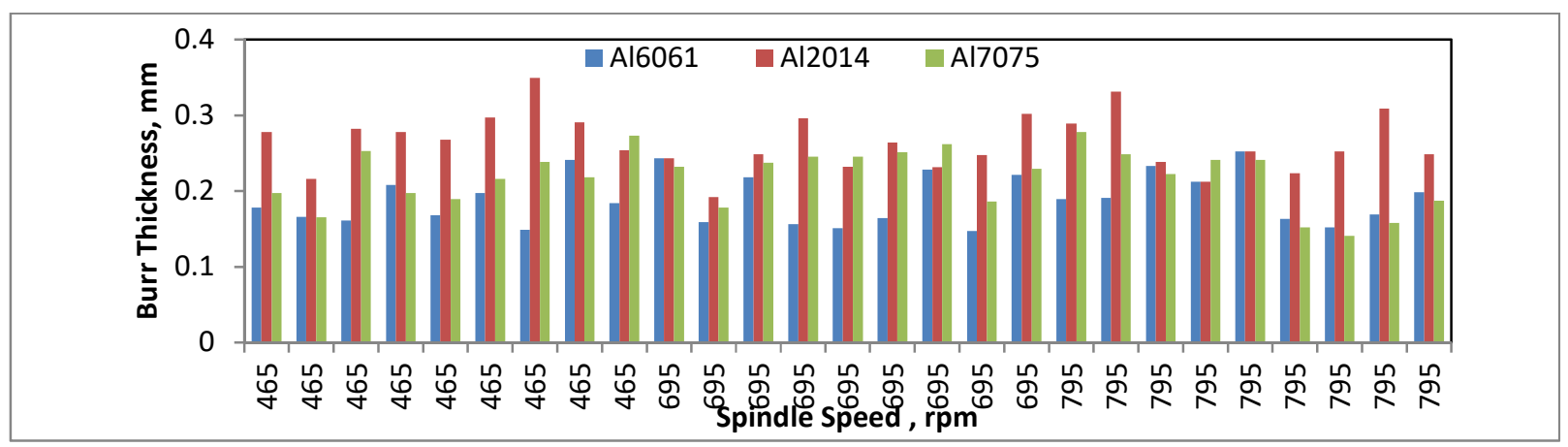

Fig. 8. Persuade of the spindle speed variation on burr thickness

The graph shown in Fig. 9 reveals that maximum and minimum values of thrust force also has similar effect as mentioned in the Fig. 7 and Fig. 8 obtained for Al 2014 alloy i.e. at the higher the feed rates, point and clearance angles results into an increase in the value of the thrust force. Besides, we observed that at higher spindle speeds and lower drill geometry causes to decrease the value of thrust force.

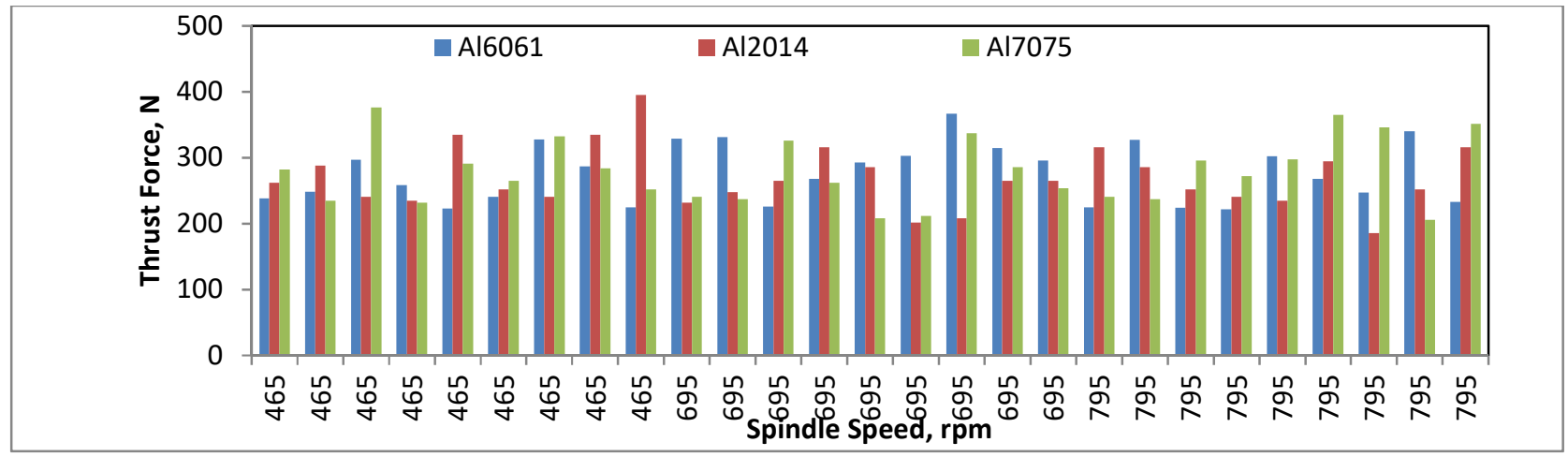

Fig. 9. Influence of variation of the spindle speed on thrust force

The observations from the Fig. 10 divulge that maximum values of torque obtained for Al 6061 alloy and Al 7075 alloy i.e. at the higher the feed rates, drill diameter and point angle yields an improvement in the value of torque. However, in contrary it is observed that the minimum torque obtained at lower ranges of spindle speeds for Al 2014 alloy. Also, it is identified that there is no influence of clearance angle on the process towards output response as torque. 


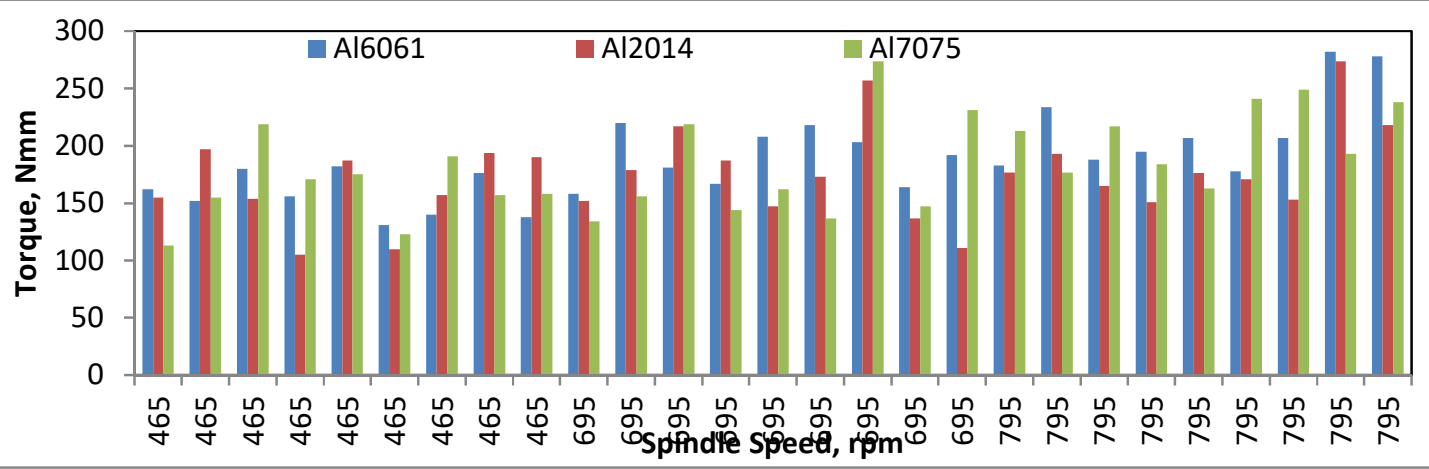

Fig. 10. Effect of variation of the spindle speed on torque

\subsection{Effect of clearance angle on output responses (SET-I)}

In the present work, complete study dealing with clearance angle effect on burr size, the graphs are plotted between the output responses versus clearance angle of drill bit at constant spindle speed $465 \mathrm{rpm}$, feed rate $18 \mathrm{~mm} / \mathrm{min}$, drill diameter $8 \mathrm{~mm}$, point angle $100^{\circ}$ (say SET-1) and the results obtained is presented in the following paragraphs.

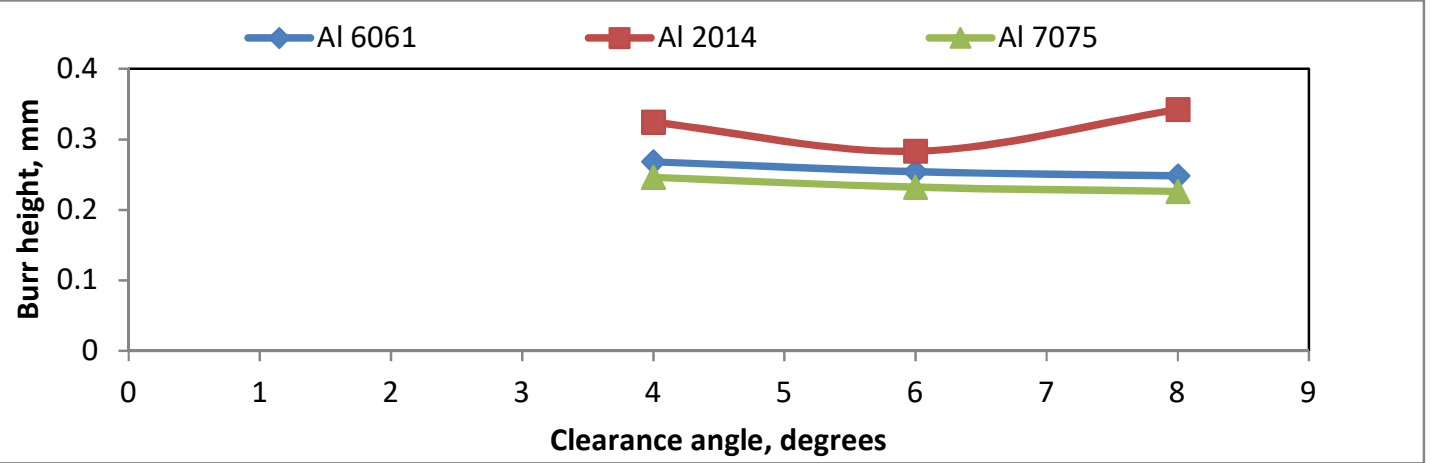

Fig. 11. Effect of increasing the clearance angle on burr height (SET-1)

The effect of clearance angle over the burr height on Aluminium 6061, 2014 and 7075 alloys during drilling are observed from Fig.11, the trends for Al 6061 alloy and Al 7075 alloy are identical, but for Al 2014 alloy decreases the size of burr height from $4^{\circ}$ to $6^{\circ}$ and then suddenly increased at $8^{\circ}$ which indicates that moderate range of clearance angle preferred especially in drilling of Al 2014 alloy. From Fig.12, observations reveal that Al 2014 and Al 7075 alloys are almost identical, out of which Al 7075 alloy produces lower burr thickness at $4^{\circ}$ clearance angle and for Al 6061 alloy decreases the burr thickness from $4^{\circ}$ to $8^{\circ}$ in a straight line relation.

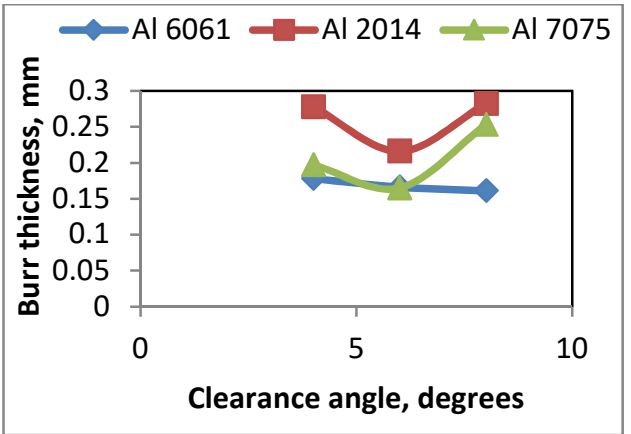

Fig. 12. Influence of increment in the clearance angle on burr thickness (SET-1)

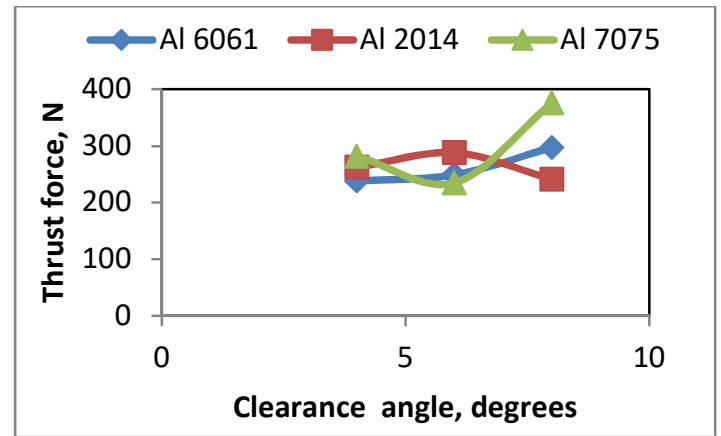

Fig. 13. Effect of modifying the clearance angle on thrust force (SET-1)

From Fig. 13, it is observed that highest thrust force generated at $8^{\circ}$ clearance angle for Al 7075 alloy and minimum thrust force obtained for $\mathrm{Al} 6061$ alloy corresponding to $4^{\circ}$ clearance angle increases proportionally to the increment in the clearance angle during drilling. For Al 2014 alloy, larger the value of 
clearance causes decrement in the value of thrust force. The output response torque is improved by increasing the clearance angle for $\mathrm{Al} 7075$ alloy comparing to the other series and moderate clearance angle results into a decrement in the value of the torque for Al 6061 alloy and the higher torque for Al 2014 alloy which is observed from Fig. 14.

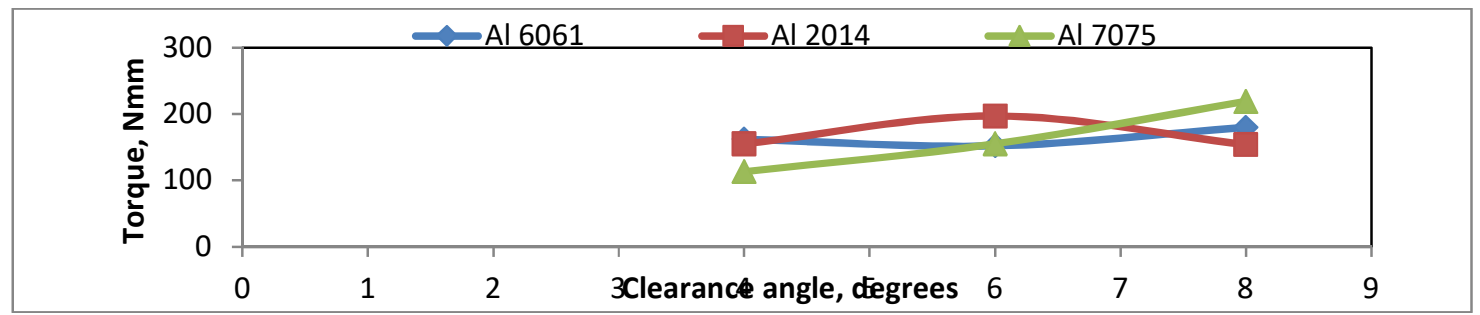

Fig. 14. Influence of alter the clearance angle on the torque (SET-1)

\subsection{Effect of clearance angle on output responses (Set-II)}

Also, the graphs are plotted the responses versus clearance angle of drill bit at constant spindle speed 795 $\mathrm{rpm}$, feed rate $26 \mathrm{~mm} / \mathrm{min}$, drill diameter $10 \mathrm{~mm}$ and point angle $100^{\circ}$ (say SET-II) and the results obtained is presented in the following paragraphs. The effect of clearance angle over the burr height on Aluminium 6061, 2014 and 7075 alloys during drilling is observed from the Fig.15, the trends for Al 6061 alloy and Al 7075 alloy are identical but for Al 2014 alloy decreases the size of burr height from $4^{\circ}$ to $6^{\circ}$ and then suddenly increased at $8^{\circ}$ which indicates that moderate range of clearance angle preferred especially in drilling of Al 2014 alloy.

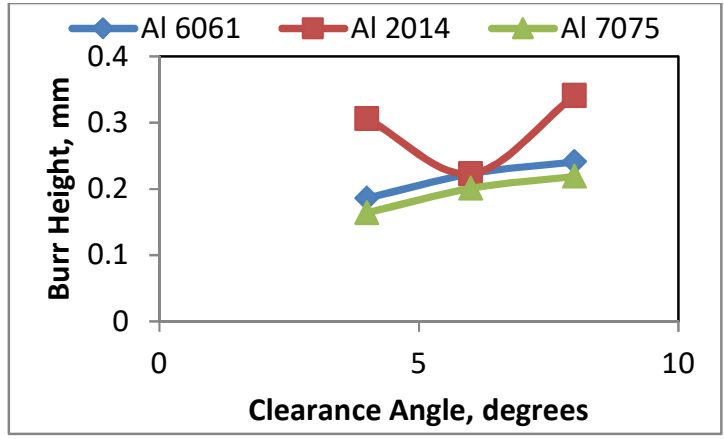

Fig. 15. Influence of variation of the clearance angle on Burr height (SET-II)

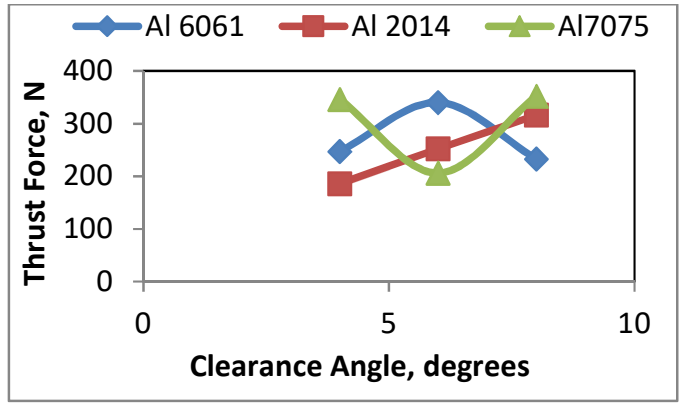

Fig. 17. Effect of variation in the clearance angle on thrust force (SET-II)

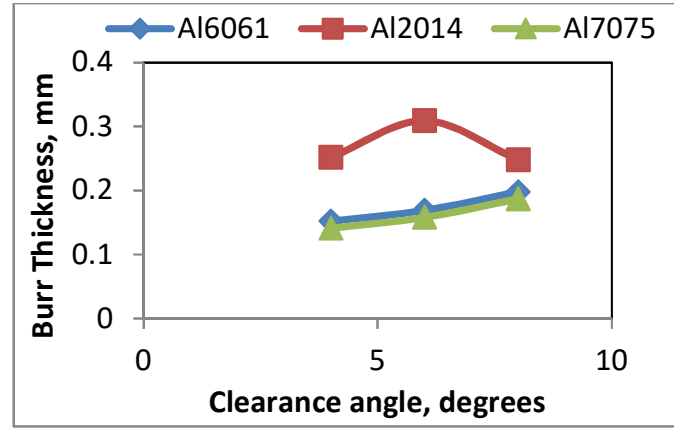

Fig. 16. Variation in the clearance angle effect on burr thickness (SET-II)

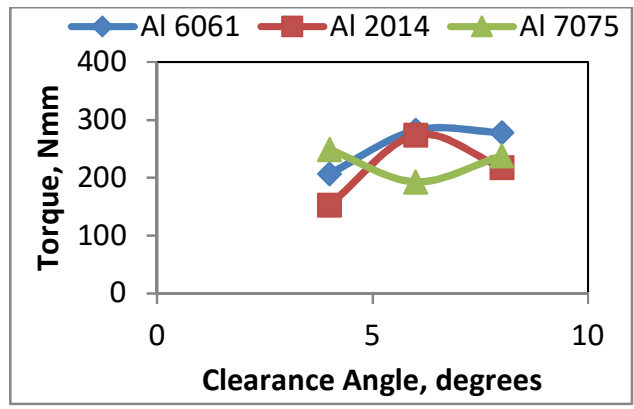

Fig. 18. Influence of variation in the clearance over torque (SET-II)

From Fig.16, observations reveal that similar trends are found for Al 6061 and Al 7075 alloys and for Al 2014 alloy, higher values of the clearance angle on drill bit causes lower the thickness of burr. The observations drawn from Fig. 17 divulges that, the thrust force is minimum at the higher values of clearance angle during drilling of Al 6061 alloy and moderate range for Al 7075 alloy to obtain minimum thrust 
force. In addition, the results reveal that an increment in clearance angle on drill bit proportionally increases the thrust force in a linear manner. From Fig. 18, the observations reveal that torque is reduced with decrease in clearance angle for Al 6061 and Al 2014 alloy and increased for Al 7075 alloy corresponding to the decrement in clearance angle. Aluminium 2014 alloy in the above graphs exhibited some sudden variations comparing to other alloys, the reasons may be

(a) Al 2014 alloy basically copper based alloy having lower yield stress (414 MPa) than Al 7075 alloy (503MPa), therefore shear deformation is less and produces thick and discontinuous chips while drilling, causes small burr height with more thickness burrs.

(b) The variation of clearance angle effect on the length of chisel edge of drill bit, so at lower clearance angle drill thrust is more to penetrate into the work piece by the drill due to less chisel edge length. Whenever increment in the clearance angle and drilling is under progress causes variation of thrust and torque. The reasons may be while drilling of Al 7075 alloy drastic changes in the output responses with variation in clearance angle as comparison to the other viz., Al 6061, Al 2014 alloys may be due to chemical composition i.e. presence of copper in alloy and variation in mechanical properties especially in the values of stresses.

To know the combined variation of thrust force and torque with respect to selecting material in drilling process, a graph is drawn by choosing both primary and secondary axes at a time and which is shown in Fig. 19. The observations from Fig. 19 reveal that Al 6061 alloy exhibits maximum thrust force and torque for the same machining conditions, the required torque is more to exert a thrust force in the case of Al 2014 alloy and at lower the torque, thrust force is higher in the Al 7075 alloy during drilling.

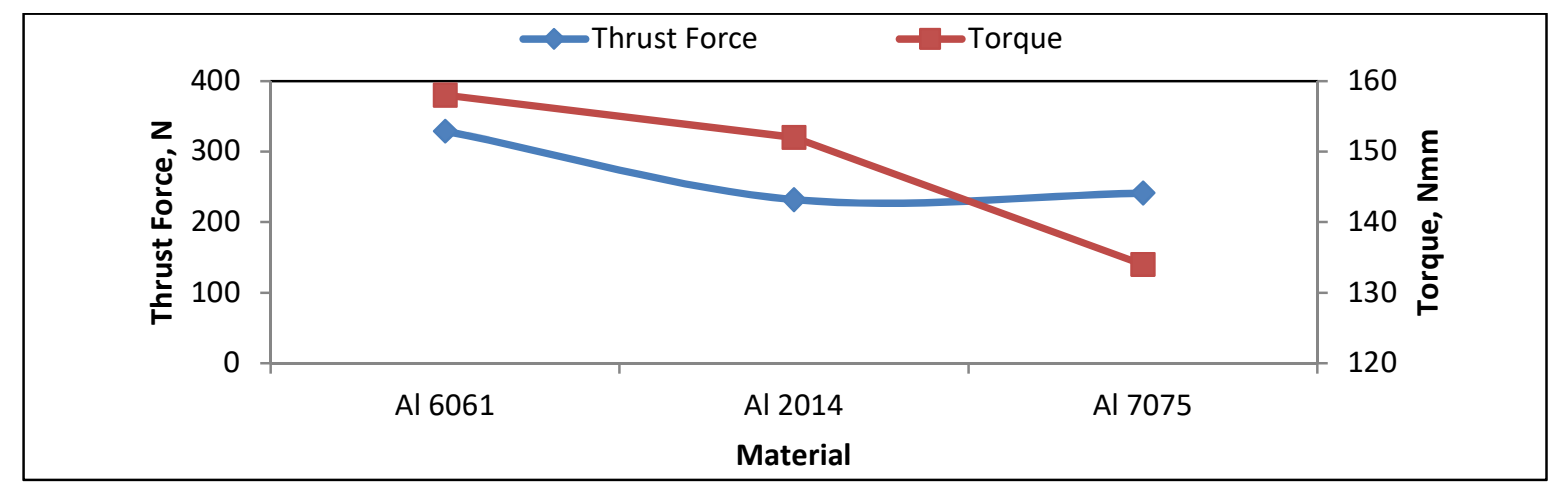

Fig. 19. Effect of thrust force and torque during drilling by the change of work piece material

\section{Conclusion}

The conclusions obtained from the present work performed to evaluate burr size (height and thickness), thrust force and torque obtained from the analytical model through MATLAB@2010 are as follows,

* The effect of clearance angle without modifying the constant ' $\mathrm{K}$ ' in the analytical modeling on the thrust force and burr height randomly and observed that the obtained values of thrust force and burr height are more than the values obtained from Analytical model (with alteration of clearance angle). It is also observed that the burr initiation height $\left(\mathrm{H}_{1}\right)$ is directly proportional to the thrust force and burr height. Therefore, it is concluded that whenever thrust force is low causes reduction in the size of burr height. An increment in the clearance angle produces lower values of thrust force also reduces the power required in drilling as well as minimizing the drilling cost. For smaller clearance angles corresponding to an increase in the values of spindle speeds and feed rates, yield an increase in the values of thrust force. 


\section{Acknowledgement}

On behalf of all authors, the corresponding author declares that there is no conflict of interest with other people published work or organizations. The submitted work should not have been published previously. Because this work is solely my $\mathrm{PhD}$ work which is submitted to Andhra University, Visakhapatnam, Andhra Pradesh, India and awarded in 2018.

\section{References}

Armarego, E. J. A. (1996). Material Removal Processes: Twist Drills and Drilling Operations. University of Melbourne, Department of Mechanical and Manufacturing Engineering, Manufacturing Science Group.

Armarego, E. J. A., \& Cheng, C. Y. (1972). Drilling wih flat rake face and conventional twist drills-II. Experimental investigation. International Journal of Machine Tool Design and Research, 12(1), 37-54.

Armarego, E. J. A., \& Cheng, C. Y. (1972). Drilling with flat rake face and conventional twist drills-I. theoretical investigation. International Journal of Machine Tool Design and Research, 12(1), 17-35.

Aurich, J. C., Dornfeld, D., Arrazola, P. J., Franke, V., Leitz, L., \& Min, S. (2009). Burrs-Analysis, control and removal. CIRP annals, 58(2), 519-542.

Chandrasekharan, V., Kapoor, S. G., \& DeVor, R. E. (1995). A mechanistic approach to predicting the cutting forces in drilling: with application to fiber-reinforced composite materials. Journal of Engineering for Industry, 117(4), 559-570.

Chandrasekharan, V., Kapoor, S. G., \& DeVor, R. E. (1998). A mechanistic model to predict the cutting force system for arbitrary drill point geometry. Journal of Manufacturing Science and Engineering, 120(3), 563-570.

Chen, W. C., Fuh, K. H., Wu, C. F., \& Chang, B. R. (1996). Design optimization of a split-point drill by force analysis. Journal of Materials Processing Technology, 58(2-3), 314-322.

Elhachimi, M., Torbaty, S., \& Joyot, P. (1999). Mechanical modelling of high speed drilling. 1: predicting torque and thrust. International Journal of Machine Tools and Manufacture, 39(4), 553-568.

Gong, Y., \& Ehmann, K. (2001). Mechanistic model for dynamic forces in micro-drilling. 19-28. Paper presented at 2001 ASME International Mechanical Engineering Congress and Exposition, New York, NY, United States.

Gong, Y., Lin, C., \& Ehmann, K. F. (2005). Dynamics of initial penetration in drilling: Part 2-motion models for drill skidding and wandering with experimental verification. Journal of manufacturing science and engineering, 127(2), 289-297.

Hirsch, J. (2011). Aluminium in innovative light-weight car design. Materials Transactions, 52(5), 818-824..

Kachanov, L. M. (2004). Fundamentals of the Theory of Plasticity. Courier Corporation.

Kapoor, S. G., DeVor, R. E., Zhu, R., Gajjela, R., Parakkal, G., \& Smithey, D. (1998). Development of mechanistic models for the prediction of machining performance: model building methodology. Machining Science and Technology, 2(2), 213-238.

Miyake, T., Yamamoto, A., Kitajima, K., Tanaka, Y., \& Takazawa, K. (1991). Study on mechanism of burr formation in drilling: deformation of material during burr formation. Journal of Japan Society Precision Engineering, 57(3), 485-490.

Oxford Jr, C. J. (1955). On the drilling of metals 1: basic mechanics of the process. Trans. ASME, 77(2), 103-111.

Sofronas, A. (1976). Effect of System Stiffness, Workpiece Hardness and Spindle Speed on Drilling Burr Thicknesses. SME Tech. Paper.

Stephenson, D. A., \& Agapiou, J. S. (1992). Calculation of main cutting edge forces and torque for drills with arbitrary point geometries. International Journal of Machine Tools and Manufacture, 32(4), 521-538.

Strenkowski, J. S., Hsieh, C. C., \& Shih, A. J. (2004). An analytical finite element technique for predicting thrust force and torque in drilling. International Journal of Machine Tools and Manufacture, 44(12-13), 1413-1421.

Williams, R. A. (1974). A study of the drilling process. Journal of Engineering for Industry, 96(4), 1207-1215.

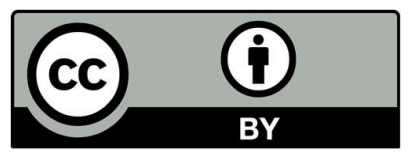

(C) 2020 by the authors; licensee Growing Science, Canada. This is an open access article distributed under the terms and conditions of the Creative Commons Attribution (CC-BY) license (http://creativecommons.org/licenses/by/4.0/). 